\title{
Thin-Film Photovoltaics 2011
}

\author{
Leonardo Palmisano ${ }^{1}$ and Gaetano Di Marco ${ }^{2}$ \\ ${ }^{1}$ University of Palermo, Viale delle Scienze, 90128 Palermo, Italy \\ 2 IPCF-CNR, Consiglio Nazionale delle Ricerche, Viale Ferdinando Stagno d'Alcontres 37, 98158 Messina, Italy
}

Correspondence should be addressed to Leonardo Palmisano, leonardo.palmisano@unipa.it

Received 30 November 2011; Accepted 30 November 2011

Copyright (c) 2012 L. Palmisano and G. Di Marco. This is an open access article distributed under the Creative Commons Attribution License, which permits unrestricted use, distribution, and reproduction in any medium, provided the original work is properly cited.

The first special issue, concerning thin-film photovoltaic (PV), was published in 2010. It covered progresses in first-, second-, and third-generation PV devices, respectively, including crystalline $\mathrm{Si}$, CdTe, and $\mathrm{CuInGaSe}_{2}$ (GIGS), organic, and dye-sensitized solar cells that mimic natural photosynthesis. Even today, many researchers are involved to find efficient methods and materials to generate electricity in clean, renewable, sustainable, and economic way. Many of them are convinced that solar energy is able to provide valuable assistance to the world energy needs. In addition, due to apparent global economic crisis, many governments have tried to promote significant public and private investments in order to create new and more numerous jobs. In this special issue are presented scientific papers which also cover theoretical and technical aspects to encourage growth in the PV field. We wish to express our thanks to all the authors who have made this publication possible, and a brief summary of all the eighteen accepted papers is below.

In " $\mathrm{TiO}_{2} /$ chitosan- $\mathrm{NH}_{4} \mathrm{I}\left(+\mathrm{I}_{2}\right)$-BMII-based dye-sensitized solar cells with anthocyanin dyes extracted from black rice and red cabbage," dye -sensitized solar cells (DSSCs) using anthocyanin dye and polymer electrolyte with ammonium iodide $\left(\mathrm{NH}_{4} \mathrm{I}\right)$ salt are presented. A study, taking into account different dyes, electrolytes, $\mathrm{PH}$, and other parameters, is carried out. Photovoltaic performances are shown and discussed.

In "Performance of dye-sensitized solar cells with (PVDFHFP)-KI-EC-PC electrolyte and different dye materials," a polymer electrolyte with poly(vinylidene fluoride hexafluoropropylene) matrix (PVDF-HFP) is used in DSSCs. The cells' performance with different dyes such as $\mathrm{N}_{3}$, anthocyanin, and chlorophyll are compared. The multidye natural mixture shows interesting conversion efficiency.
In "A convenient method for manufacturing $\mathrm{TiO}_{2}$ electrodes on titanium substrates," the possibility of developing microplasma oxidation (MPO) method to prepare $\mathrm{TiO}_{2}$ thin films, useful to achieve photoanodes for DSSCs devices, is presented. Photoelectricity properties and morphology of the films are investigated.

In "Influence of parameters of cold isostatic pressing on $\mathrm{TiO}_{2}$ films for flexible dye-sensitized solar cells," cold isostatic pressing (CIP) is used to make $\mathrm{TiO}_{2}$ working electrodes for flexible DSSCs. A study varying pressures and holding time, supported by electrochemical impedance spectroscopy (EIS) analysis, is performed on the working electrodes.

In "Indium-doped zinc oxide thin films as effective anodes of organic photovoltaic devices," indium-doped zinc oxide (IZO) thin films are prepared by low-cost ultrasonic spray pyrolysis (USP). The IZO films are investigated as anodes in bulk-heterojunction organic photovoltaic (OPV) devices, and photoelectrochemical parameters are shown.

In "Theoretical insight into the spectral characteristics of $\mathrm{Fe}(\mathrm{II})$-based complexes for dye-sensitized solar cells-part I: polypyridyl ancillary ligands," a theoretical investigation on a series of polypyridyl $\mathrm{Fe}$ (II)-based complexes, as sustainable dyes for DSSCs, by density functional theory (DFT) and time-dependent DFT (TD-DFT) is performed. Compared with $\mathrm{Ru}$ (II) sensitizers, $\mathrm{Fe}(\mathrm{II})$-based complexes show interesting characteristics.

In "Optimization of recombination layer in the tunnel junction of amorphous silicon thin-film tandem solar cells," amorphous silicon/amorphous silicon (a-Si/a-Si) tandem solar cells are fabricated by high-frequency plasma-enhanced chemical vapor deposition (HF-PECVD). Recombination and the intrinsic layer thickness effects, on the device performance, are investigated. 
In "Three-terminal amorphous silicon solar cells," new three-terminal a-Si p-i-n/n-i-p solar cell, with low recombination rate of photogenerated carriers, is conceived. A comparison between the two-terminal a-Si p-i-n solar cell (control cell) and the former is done.

In "Characterization of nano-crystalline SiGe thin film solar cell with double graded-dead absorption layer," nanocrystalline silicon-germanium (nc-SiGe) thin films, obtained by plasma-enhanced chemical vapour deposition (HFPECVD), are used in a silicon-based solar cell. Spectroscopic, microscopic analysis and $I-V$ characterization of the cells are shown.

In "Effect of p-layer and i-layer properties on the electrical behaviour of advanced a-Si:H/a-SiGe:H thin film solar cell from numerical modeling prospect," a two-dimensional computer simulation in amorphous silicon band-gap for the optimization of the single-and double-junction hydrogenated amorphous silicon-germanium solar cells is presented. The electrical, photogeneration, and recombination rate behaviours are investigated.

In "Progress in thin film solar cells based on $\mathrm{Cu}_{2} \mathrm{ZnSnS} \mathrm{S}_{4}$," the paper reviews the wide range of techniques that have been used to deposit $\mathrm{Cu}_{2} \mathrm{ZnSnS}_{4}$ (CZTS) semiconductor thin films. The performance of the thin film solar cells using the CZTS material is discussed.

In "Tailoring the composition and properties of sprayed $\mathrm{CuSbS}_{2}$ thin films by using polymeric additives," spray pyrolysis and polymeric additives, to prepare $\mathrm{CuSbS}_{2}$ thin films, are used. These are characterized by morphological and spectroscopic points of view. The polymeric additives represent a powerful tool for developing efficient $\mathrm{n}$-p junctions in solidstate solar cells.

In "Preparation and characterization of coevaporated $C d_{1-x} Z n_{x} S$ alloy thin films," homogenous $C_{1-x} \mathrm{Zn}_{x} \mathrm{~S}$ thin films are prepared by the vacuum coevaporation of CdS and $\mathrm{ZnS}$. Structural, composition, and optical properties are investigated. A novel $\mathrm{Cd}_{0.4} \mathrm{Zn}_{0.6} \mathrm{~S}$ layer is introduced in the $\mathrm{CuInS}_{2}$-based solar cells.

In "Achievements and challenges of CdS/CdTe solar cells," the paper summarizes the latest research and techniques to solve the efficiency problem in CdS/CdTe photovoltaics. It is believed that these devices are good candidates for future low-cost solar cells, so new ideas are offered for further development.

In "Polarity switchable photovoltages in miscut $\mathrm{La}_{0.67} \mathrm{Ca}_{0.33} \mathrm{MnO}_{3}$ films," a potential application of the manganite film as photodetector is provided. This idea emerges from the photovoltaic effects observed in the $\mathrm{La}_{0.67} \mathrm{Ca}_{0.33} \mathrm{MnO}_{3}$ (LCMO) film and $\mathrm{LaSrAlO}_{4}$ (LSAO) substrate under pulse laser irradiation.

In "Load resistance- and voltage-tunable photovoltaic effect in tilting manganite films," the photovoltaic properties of miscut $\mathrm{La}_{2 / 3} \mathrm{Ca}_{1 / 3} \mathrm{MnO}_{3}$ films are investigated. The photoresponse depends on bias voltage $(\mathrm{Vb})$ and load resistance $(R S)$. The obtained results suggest potential optoelectronic applications.

In "Efficiency considerations and application limits of single-phase active power filter with converters for photoenergy applications," a new way of connecting PV sources to adaptive voltage active power filter (AVAPF) is compared with classic approach including active power filter (APF). Experimental results confirm expectations of increased energy transfer from additional DC source to network.

In "Charge-carrier transport in thin film solar cells: new formulation," is reported that conventional solar cells plays a major limiting role in the cell efficiency. Moreover a new formulation of the basic equations describing charge-carrier transport in the cell along with a set of boundary conditions is presented.

Leonardo Palmisano Gaetano Di Marco 


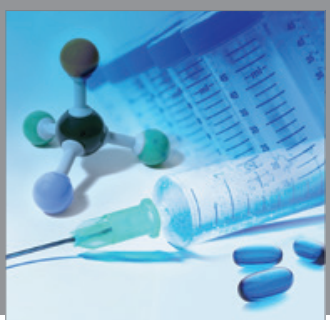

International Journal of

Medicinal Chemistry

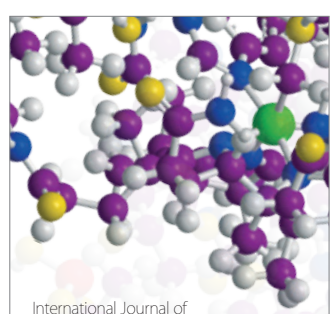

Carbohydrate Chemistry

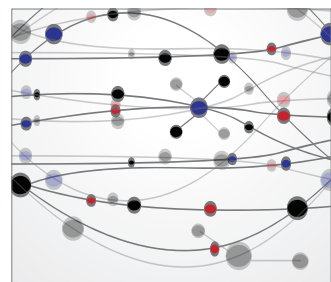

The Scientific World Journal
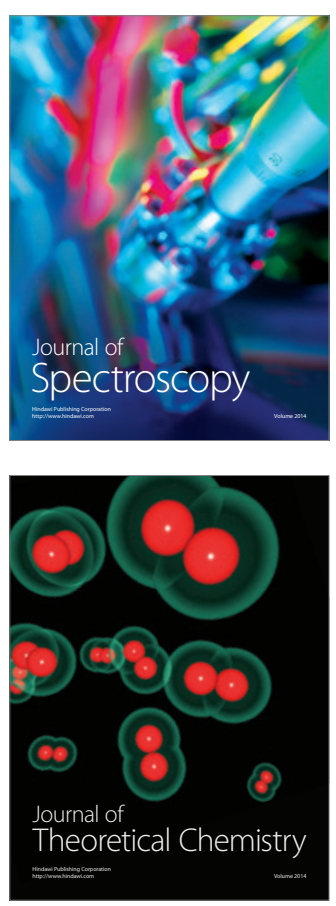
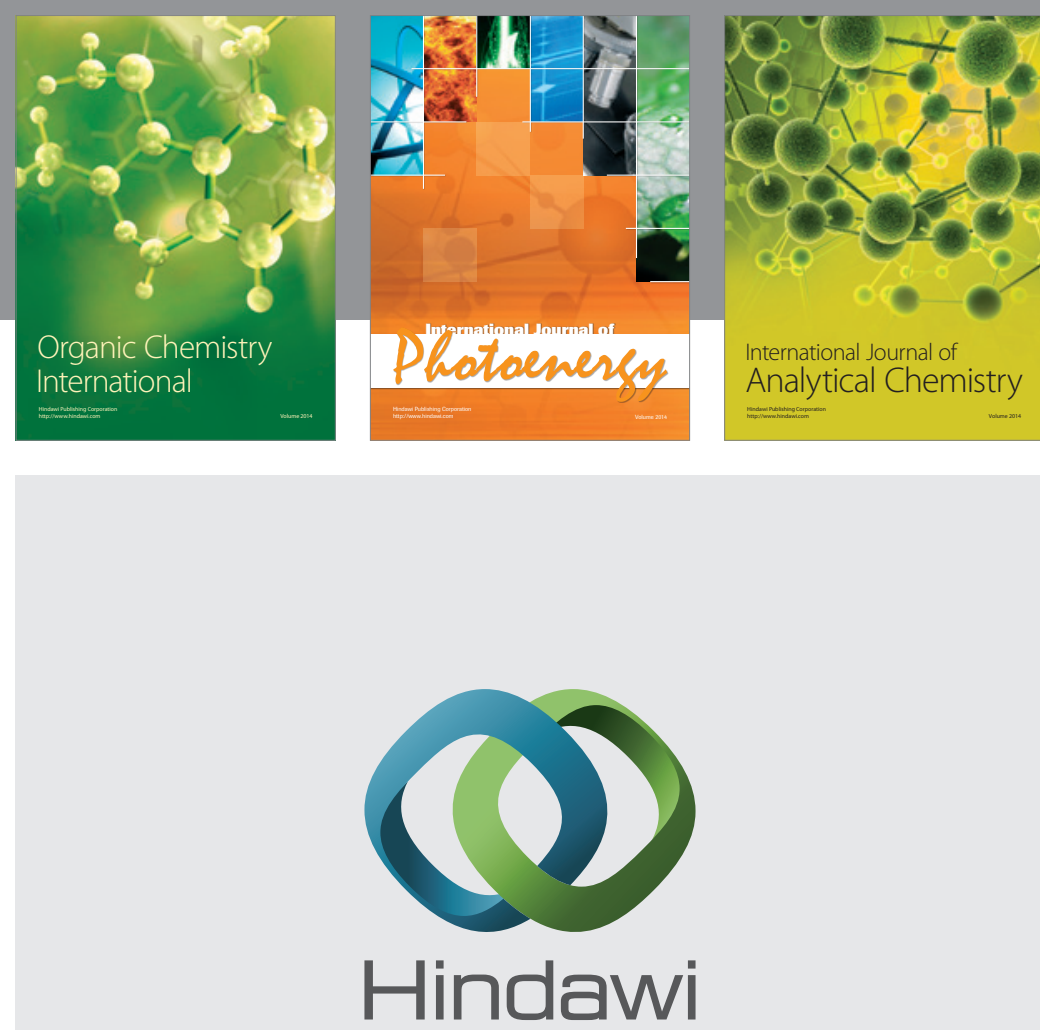

Submit your manuscripts at

http://www.hindawi.com
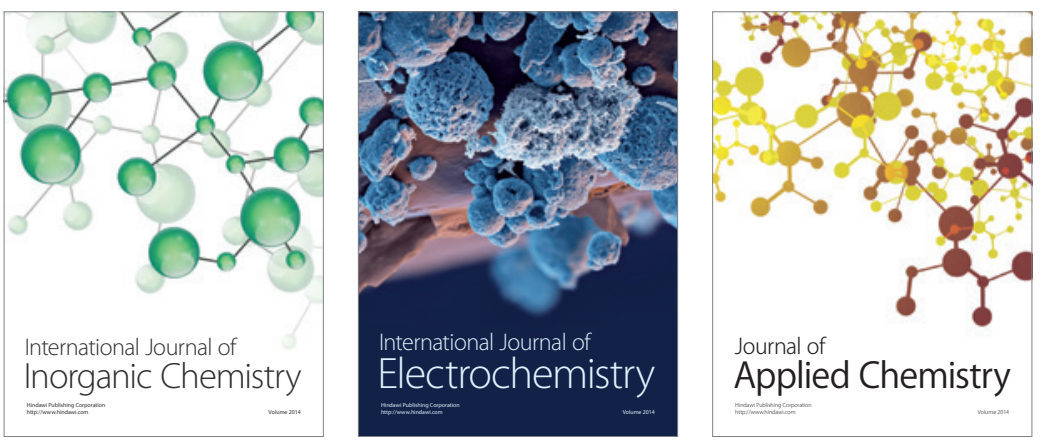

Journal of

Applied Chemistry
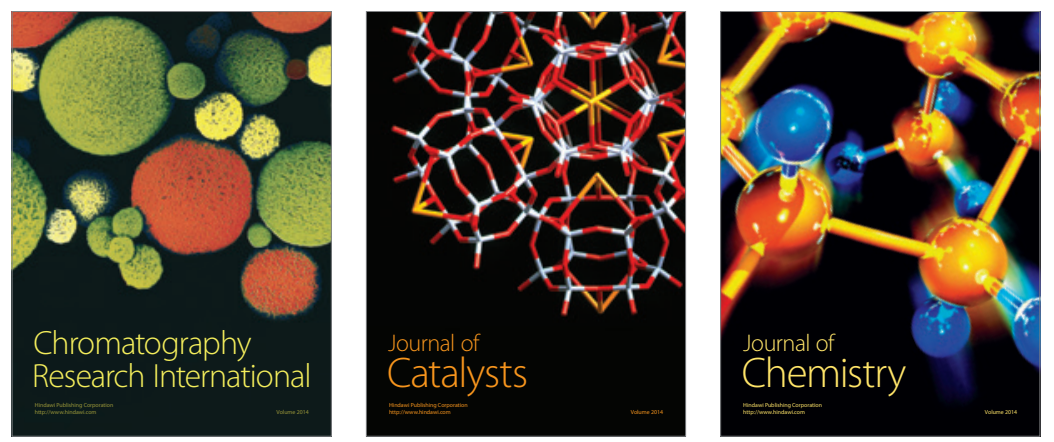
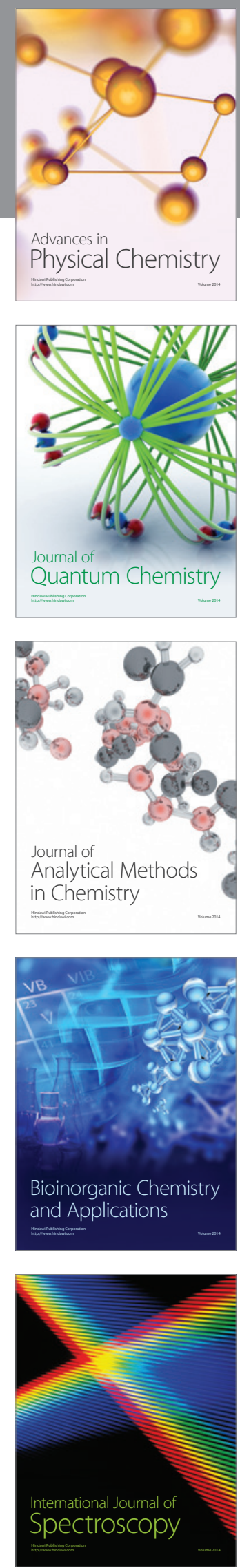